\title{
A CENTRAL OPHTHALMOLOGICAL INSTITUTE FOR THE UNITED NATIONS*
}

BY

\author{
Professor ARnold Loewenstein (Pragure) $\nmid$
}

I STARTED many years ago an enquiry in University circles into how my colleagues came to take up their academic career, especially whether there had been an old desire to become a professor or a leaning towards teaching and' research. With few exceptions, and these were the sons of professors, I got the answer that chance had ruled their fate; a junior vacancy, a scholarship or a fortuitous personal contact with the head of a department had induced these later-more or less successful men to take up an ácademic career.

There is no doubt that chance may give birth to excellent products, but if we want to create the optimum, we cannot rely on chance-until by mutation the right gene develops. If we want to produce good doctors who are urgently needed, we must create first class teachers of medicine. As the profession itself realises that these conditions are so far unsatisfactory we must plan to improve them. There is no doubt that a genius can learn our handicraft unsupported, and discover himself many well known facts with a terrible waste of time and labour. It is in the interest of the nations that the learner should learn the best in the shortest time, so that he can use his knowledge as long as possible to the benefit of the people. To reach this aim we must improve selection and training of the teacher.

- A plan is here proposed to create a centrè of medical education,. according to the writer's restricted experience in ophthalmology only, from which perfectly trained clinicians will rise with the highest standard of scientific experience, to become all-round clinical chiefs trained to take over. the teaching of the medical schools.

As such an institute will be expensive very great units only are suitable for this purpose, although private initiative and private charity may facilitate its organisation. I have in mind a common central institute of ophthalmology for the United Nations. Parallel institutes for other subjects ought to follow. They may be distributed over the big towns of the nations according to where they are needed and where there are suitable teachers available. In the near future the common budget of the allied nations will be considerable. The idea' of a common education must not be forgotten. The central medical institutes are part of it and all - nations will enjoy the fruits of their work.

* Received for publication, May 1, 1944.

† From the Tennent Institute for Ophthalmology (Professor W. J. B. Riddell) ‘ Glasgow. 


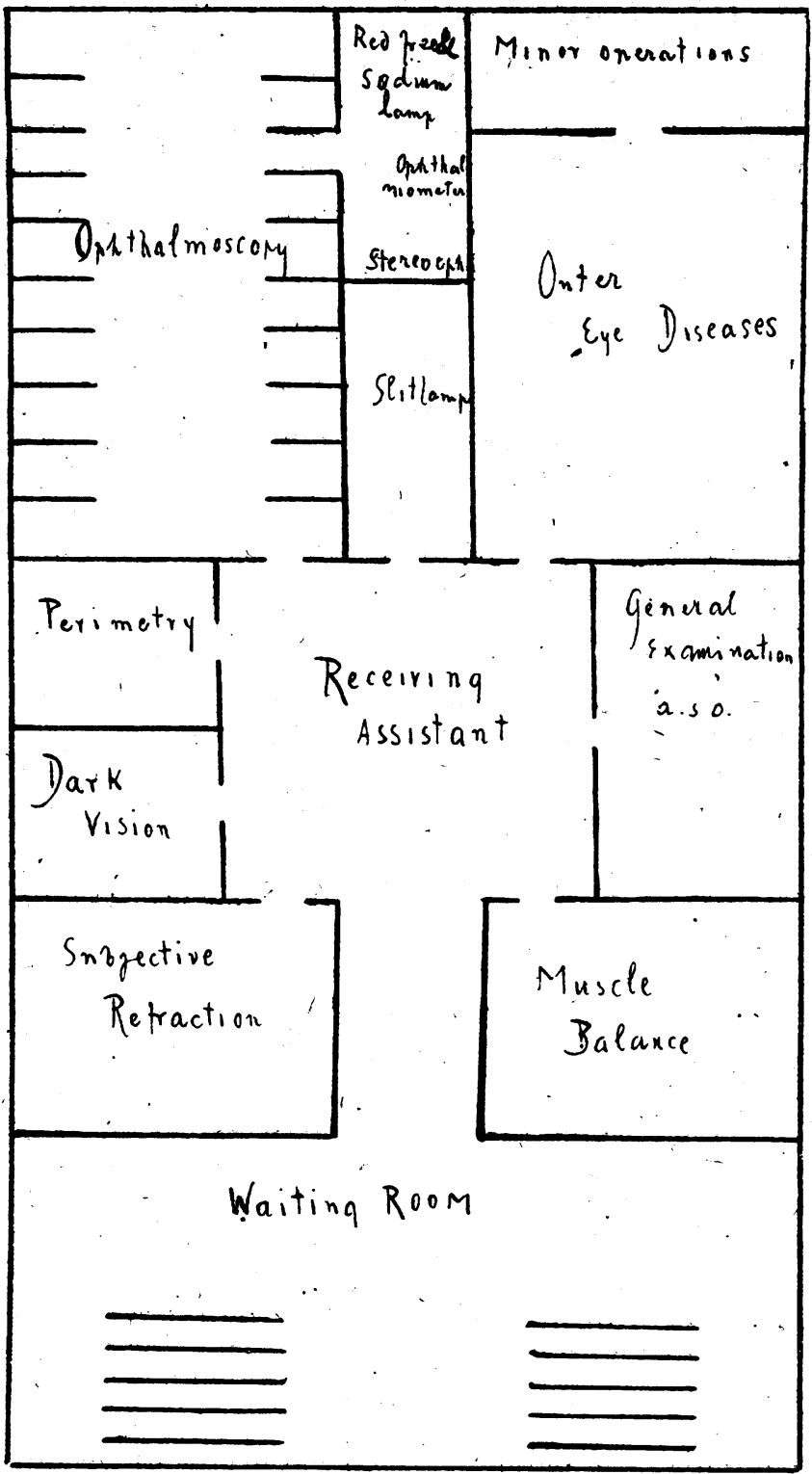

A blueprint only of such an institute is offered here, but it is far from perfect. It pretends to contain no more than some ideas collected.by observation and work in different clinics, experiences gained in teaching and investigation in different countries; and last but not least; it is written with knowledge of certain deficiencies of our present system.

The new institute can scarcely be housed in one of the older 
buildings. It ought to be constructed according to modern hospital architecture, which is a relatively new branch of building technique. Careful investigation of the new eye hospitals, especially in America and Russia, is necessary, attention being paid to the question of where they have proved unsatisfactory. That can be done by personal discussion only with the respective surgeons and administrators. Nobody doubts that an institute in an over-crowded centrally situated city is unsuitable, but it ought to be readily accessible by good and cheap traffic lines.

A young energetic m̀an or woman with initiative and a creative imagination must take the lead, not hampered by historic or any other prejudice. This leader need not necessarily be a great scientific investigator, but a good general knowledge of ophthalmology and especially a good operative mind with manual dexterity are necessary. The latter would not be essential provided the head of the, institute would restrict himself to responsible leadership and leave the surgical work to a specially gifted subchief. The main task of the chief is the choice of his collaborators, and continuous inspiration of all his juniors. Each individual department has its own subchief, but the leader must ensure close collaboration between all the departments. His position requires great independence and the task of administration will absorb much of his energies.

How to organise such an institute? There ought to be a large outpatients' department as this ensures the necessary variety of cases. It is expected, of course, that the whole country will, in due time, send the difficult cases to this institute, which will thus have the best and selected clinical material. Nevertheless, the outpatients' department remains the most important part of the institute and ought to be built and organised in a perfect manner. I have not yet seen an outpatients' department which was satisfactory in every way, a very difficult task it seems:

-There will be a large reception hall (with cloakrooms) for the public to, wait in with interesting pictures on the walls, pamphlets on heredity, venereal diseases, glaucoma, etc., for the grown ups to read and easily disinfected toys for the children. The waiting time should be short as there is a sufficiently large staff to cope with the numbers of patients. The clerical work is done there, the case history typed, general anamnesis done and visual acuity noted. The patient passes straight on to a central room, where the receiving assistant is the first specialist to see the patient. He completes the anamnesis according to his diagnosis-typed again and directs the patient to one or more of the cubicles with cards $(1,2,3 \ldots$ according to what is needed). When all the examinations are finished the patient returns to the receiving assistant who 
either orders the therapy, checks the ordered glasses and dismisses the patient, or orders any other examinations which might be necessary, or keeps him for admission or introduction to the chief. It is clear that only an experienced assistant is suitable for this responsible job. Before the patient is dismissed the social worker enters in her own. She takes notes from suitable cases, where heredity plays a part, where the influence of surroundings is not to be neglected. Psychological injuries escape easily the attention of the busy clinician, she may be of great value in the case of neglected children, and of glaucoma clinics (M. Schoenberg).

The two biggest cubicles are to the right and left where the external diseases are treated on one side and the ophthalmoscopy is done on the other. The external diseases room is the brightest in the whole building with plenty of windows-some of them should have small panes for examining the corneal reflex. Some perfectly equipped treating tables are placed in the room, one each for two doctors and one nurse. There must never be a crowd in this room and nobody must be kept waiting here. An operating chair of simple construction is necessary for small incisions, hordeolä, tonometer readings, etc. One corner with a microścope is reserved for smears, cultures, etc. The presence of a photographic cabinet near the outpatient room would save time.

The large room opposite is, reserved for, ophthalmoscopic examination, with cubicles for ophthalmoscopy and skiascopy. If there are many cubicles available this room may be used for teaching ophthalmoscopy in bigger classes as well. On the free walls are Red-free and Sodium-lamp-ophthalmoscopy, stereoophthalmoscope (Gullstrand) and ophthalmometer. Blackboards for explaining the fundus changes are in each cubicle. The walls are covered with the best fundus pictures from the literature so that the student of ophthalmoscopy may become familiar with them. I found it very useful to sacrifice one of the best fundus atlases, frame each picture under glass and mount them round a movable vertical axis.

The next room is the place for physical examination, blood and urine tests, where the ophthalmologist can also obtain the collaboration of an ear, nose and throat specialist and a dentist. Cases for the neurologist and other specialists may be examined elsewhere. The X-ray department and treatment with different rays is not necessarily in close connection with the outpatients' department.

A slit-lamp room is equipped with all modern instruments and also there is a perimeter room and a room for dark adaptation and night vision tests, all to be entered from the central space. The special room for subjective refraction should be large with several sets of test types, etc. Examination of muscle balance may be 
combined with the orthoptic department. Each of these rooms is in charge of one assistant. The rotation of the assistants and their periods of duty in the departments may be fixed; but the rule ought to be elastic, and individual wishes should be considered as far as possible. It is easily understood that an assistant who dedicates all his time and his brain to his special work will learn more than to do routine work and will soon contribute to actual progress and research.

The most important hour of the day is the staff meeting; when the interesting cases from the outpatients' department are considered. Discussion of the cases is initiated by the reporting assistant, then follow questions by the inexperienced, reports from the seniors, explanation, if possible with demonstration of histological slides of the clinical collection, mention of cases in the literature; all these factors make such an hour far superior to the best : postgraduate lecture. It is most important that the whole staff should take part at these meetings, the presence of the members of the laboratory staff being especially valuable.

The rooms for inpatients must not be large; they must be strictly aseptic with huge windows, best made of a material permeable to ultra-violet rays. Several small modern theatres are preferable to one large one. They should be close to one another to enable the visitors to see more operations in a given time. It is necessary that this institute should perform rare operations too, and accept sensible innovations of technique as the first. The whole ophthalmic world will listen to and take note of its constructive eriticism. As it is a teaching hospital asepsis cannot be overdone.

The rounds of the chief with the whole staff, twice a week, complete the daily staff meetings of the outpatients' department. Again questions and answers are the vehicle of progress. These rounds are necessarily performed at a very early hour as the staff will be busy during the outpatients' periods. For the same reason operations should be performed early in the day too.

The laboratory is the centre of the afternoon activity of the staff, as the histological laboratory is the source of deeper understanding of physiology and pathology of the eye. Histology does not belong to the past, but is, according to my conviction, at its beginning as yet. New methods of investigation ought to be introduced, and the results will be amazing. Bacteriology of the eye, especially the study of the virus diseases, is in its infancy. The electron microscope will be the instrument of many future investigators of eye diseases. Tissue culture, chemical, physicochemical, optical and physiological activity require special training and are not strictly included in the curriculum of the institute. They are available only to special investigators. But the whole staff will learn at least something of this work from the reports of 
the specialists in the'evening staff meetings which are reserved for scientific reports in the narrower sense.

The department of photography, including 'cinematography, colour photography; fundus photography and photomicrography is an essential part of the institute I am describing. An artist of special gifts is in charge of the clinical, especially the fundus pictures, and he ought to supervise the work of his apprentices. There will be a great need of scientific artists, and a higher estimation of their work than exists nowadays when they remain frequently anonymous. Many young artists will take up such a career.

- Promising young men will find in such an institute all that teaching can offer in a concentrated form. They have to pass through all the departments, including the laboratories. These men become real all-round clinicians, a very rare thing to-day even with excellent clinical teachers. Most of them restrict their work to one or some sections only of our subject. It is easily understood that postgraduate teaching will find a very suitable home in this institute generally.

Scientific production has ideal conditions in this central insti- tute. The library must contain the specialistic as well as part of the general medical literature of all nations. Linguistic difficulties in reading papers in a foreign language are removed by a special auxiliary staff who are available also to other institutions. The position of such an institution in the scientific world will be dominant, its production of high value and correspondingly regarded.

We ophthalmologists suffer from the lack of a journal with careful reports of the contemporary literature compiled quickly after the publication of the original article. Such an instituté would be the right place for professional men to do the job. Experienced scientists only are able to give a short and exhaustive summary of a paper with a certain degree of ćriticism allowed:

Who may enter this Mecca of ophthalmology? All the promising young men and women of the eye clinics of the United Nations have a right to apply. Those with the best qualifications, in a wide sense of the word, are admitted, first for a restricted period. They become members of the staff later according to the judgment of their seniors. The best of the juniors are elected to senior posts and out of the seniors the teachers of ophthalmology will arise all over the civilized world.

The ophthalmic centre keeps its staff active from chief to the youngest assistant from morning till night. All have a full time job, therefore a private practice in the common sense is absolutely excluded. The salary of all employees is modest but sufficient to live an independent life, Securities for old age in the form of a 
peńsion for retired workers are needed. It is not necessary to emphasise the great honour of being a member of this institute. The nomination of outstanding foreign' ophthalmologists as corresponding members of the institute would stress its international character.

There is no time or space here to deal with linguistic difficulties, but we stress the fact that all the governments of the United Nations accepted English as the second language. The knowledge of English or of Basic English will spread to a hitherto unknown extent. Or an artificial language will link the nations. But these difficulties are practically inconsiderable. I remember the American assistants of Elschnig's clinic in Prague 20 to 30. years ago. Most of them spoke English only, but they had no difficulty with our Czech patients. These so-called difficulties will be negligible in the near future when isolationism will be obsolete. And, finally, the population of the city in which this central institute is erected will feel rightly proud and fortunate.

I do not doubt that the old system-being no system at allwith its laissez faire, leaving all to chance without offering a fair chance to all, produced many great men.

We shall improve the selection of the able and we shall improve the conditions of training. In this way we can expect very good results.

The fact that the path we tread is a new one is no reason to refute the idea, especially in these times when progress goes forward at an increasing pace. ${ }^{*}$

\footnotetext{
On reading the proots I want to add that Joseph Needham explained-his idea of international scientific collaboration recently (Nature, Nov. 25, 1944), in a very interesting article from which concrete-proposals emerge.
} $\rightarrow$

\section{THE EYE OF THE WEST AFRICA ̀ं NEGRO*}

BY

J. Graham ScotT, Major, R.A.M.C.

GLASGOW

THERE are certain differences between West African and European eyes which are noteworthy.

1,000 Gambian schoolchildren, 1,100 Gambian, 300 Gold Coast, 300 Nigerian and 300 Cameroon soldiers were examined in addition to hospital and out-patients seen at a West African Military Hospital over a period of 18 months.

The most obvious difference was pigmentation [mentioned by Duke-Elder (19302)]. Ninety per cent. of African soldiers presented

\footnotetext{
* Received for publication June 9, 1944
} 